\title{
Modelagem Matemática das Ondas de Marés Astronômicas
}

\author{
João Socorro Pinheiro Ferreira Nágela Rafaela Bastos Silva ${ }^{1} *$ \\ Jailson da Silva e Silva Márcia Valéria Trindade dos Santos \\ Colegiado de Licenciatura em Matemática, UNIFAP, \\ 68.903-419, Macapá, AP \\ E-mail: joaoferreira@unifap.br_nagela_bastos@hotmail.com \\ jailson876@hotmail.com marcinha_glomerinha@hotmail.com
}

\begin{abstract}
RESUMO
Neste Trabalho de Iniciação Científica visa mostrar a Matemática Aplicada como meio de descrever situações reais através de modelos matemáticos. Como foco principal, trabalharamse as ondas de marés astronômicas com o objetivo de elaborar uma modelagem matemática para a simulação destas ondas. Segundo Sato ${ }^{5}$, 2010, as ondas de marés observadas acontecem como resposta a interação de vários fatores como os efeitos regionais e locais, a meteorologia e, principalmente, a resposta da bacia oceânica às forças geradoras de maré: forças astronômica. Ainda segundo a autora, trata-se de uma interação entre Sol, Lua e Terra. Isso acontece devido a força gravitacional entre o Sol e a Terra e entre a Lua e a Terra. Assim acontecem as preamares e baixares, respondendo a este ciclo astronômico. Os cálculos das alturas das ondas de marés foram determinados usando séries de Fourier e as equações resultantes foram obtidas pelo método dos mínimos quadrados, com base nas obras de Figueiredo ${ }^{2}$, 1977, e Aguiar e Moreira Junior ${ }^{1}$. Estes cálculos foram automatizados com o uso dos softwares matemáticos Excel e Scilab, ambos gratuitos. Foi obtido um modelo matemático que representa o movimento das ondas de marés utilizando-se de dados obtidos através da Tábua de Marés localizada no Estado do Amapá, mostrando a importância e a necessidade destes cálculos uma vez que A previsão das alturas marés é um fator de grande importância para a navegação. Para isso é necessário um conjunto de informações e um cálculo bem determinado para estimar essa previsão da variação do nível do mar.
\end{abstract}

Palavras-chave: modelagem, matemática aplicada, ondas de marés astronômicas.

\section{Referências}

[1] AGUIAR, FL; MOREIRA JUNIOR, W I. Ajuste de curvas por quadrados mínimos lineares. Departamento de Matemática UFMG. Disponível em < http://www.mat.ufmg.br/gaal/aplicacoes/quadrados_minimos.pdf> Acesso em 13 Fev 2013.

[2] FIGUEIREDO, Djairo Guedes de. ANÁLISE DE FOURIER E EQUAÇÕES DIFERENCIAIS PARCIAIS. Rio de Janeiro, Instituto de Matemática Pura e Aplicada, CNPq, 1977.

[3] GUIDI, L F. Introdução ao Scilab. Disponível em <http://www.mat.ufrgs.br/ guidi/grad/MAT01169/laminas.Intro_Scilab.pdf>. Acesso em 30 Jan 2013.

[4] Marés e Correntes de Marés; Correntes Oceânicas. Disponível em < https://www.mar.mil.br/dhn/bhmn/download/cap10.pdf >. Acesso em 20 Ago 2013.

\footnotetext{
${ }^{1}$ Bolsista de Iniciação Científica do Programa PROBIC - UNIFAP.
} 
[5] SATO, Olga. ONDAS E MARÉS. Universidade de São Paulo, 2010. Disponível em: < http://www.io.usp.br/tiki-index.php?page=Olga_Sato >. Acesso em 9 Agosto de 2012.

[6] Tábuas de Marés: BARRA NORTE DO RIO AMAZONAS-PONTA DO CÉU (ESTADO DO AMAPÁ). Disponível em <https://www.mar.mil.br/dhn/chm/tabuas/10653Jan2013.htm> Acesso em 30 Ago 2012. 